\title{
À BEIRA DE ESPELHOS. ROLAND BARTHES FRAGMENTÁRIO
}

Rodrigo da Costa Araújo é Professor da FAFIMA - Faculdade de Filosofia, Ciências e Letras de Macaé, Mestre em Ciência da Arte pela UFF/ Universidade Federal Fluminense e Doutorando em Literatura Comparada, também, pela UFF.

E-mail: rodricoara@uol.com.br

\begin{abstract}
Resumo
A escritura-leitura de Roland Barthes (1915-1980) concilia as margens do ensaio e do romance e realiza, transgressoramente, a inscrição do romanesco no texto crítico. Nesse sentido, essa comunicação foca o livro-corpus Roland Barthes por Roland Barthes (1975) que possibilita a concepção de um texto plural e promove a noção semiológica do autor em substituição do conceito de um "eu" da escritura. Esse sujeito, estilhaçado e romanesco, situa-se no universo semiótico, "ordena" sua vida na escrita, junta os fragmentos para compor uma imagem labiríntica e reinterpretada de diversos modos sígnicos, tais como construção de uma imagem de si na trama das palavras ou na figuração de um sujeito que se desdobra na sua diversidade polifônica. A leitura desses "eus", consequentemente, faz do leitor um criador de texto, ou seja, ele assume, também, o lugar da escritura.
\end{abstract}

PALAVRAS-CHAVE: Roland Barthes fragmentação - Roland Barthes por Roland Barthes

\begin{abstract}
Résumé
L'écriture-lecture de Roland Barthes (1915-1980) concilie les marges de l'essai et du roman et $y$ inscrit, de façon violée, le romanesque dans le texte critique. Dans ce sens, ce essai focalise sur le livrecorpus Roland Barthes par Roland Barthes (1975) qui procure la conception d'un texte pluriel et promouvot la notion sémiologique de l'auteur en substuition au concept d'um "je" de l'écriture. Ce sujet, fragmenté et romanesque, se situe dans l'univers sémiotique, mène as ne das l'écriture, réunit les fragments pour composer une image labyrinthique et réinterprétée de plusieurs manieres de significations, ainsi que la construcion d'une image de soi-même dans la trame des mots ou dans la figuration d'um sujet qui se déploie en sa diversité polyphonique. La lecture de ces "je”, par conséquent, fait du lecteur um créateur du texte, c'est-à-dire, il assure aussi lê lieu de l'écriture.
\end{abstract}

$\begin{array}{lll}\text { MOTS-CLÉS: } & \text { Roland } & \text { Barthes - } \\ \text { fragmentation - Roland Barthes par } \\ \text { Roland Barthes }\end{array}$

Escrever é antes de mais, pôr o sujeito (incluindo o seu imaginário de escrita) em citação, romper qualquer cumplicidade, qualquer enviscamento entre quem traça e quem inventa, ou melhor ainda, entre escrever e quem (re) lê.

[BARTHES, Roland. Sade, Fourier, Loyola. 1990 p. 123].

\section{VERTI GENS, CRÍ TI CA E AUTO-CRÍ TI CA EM ABI SMO}

Referir-se a Roland Barthes [1915-1980] parece, desde já, aceitar algum pacto, alguma apresentação - óbvia e obtusa - ao seu modo - procurando obter "um primeiro traço da figura, e que contenha já um pouco do seu ar, um sinal de alma, um certo punctum" ", aquele que permite, segundo Roberto Correia dos Santos, "um esboço, de um retrato, de uma foto" (SANTOS, 1999, p.93).

Nesse pacto ${ }^{2}$, ao mesmo tempo demarcado como l'obvie et l'obtus -, não ficam claras as regras do percurso barthesiano, ficam apenas os vestígios de uma 
força escritural voltada para a concepção do texto como híbrido entre ensaio e romanesco. Por isso esse mesmo ensaio, como o próprio assunto retratado, assume, como o semiólogo, o próprio desejo de rejeitar a repetição, a tese, a doxa, isto é, a autoridade, optando pelo corte, pelo zigue-zague, pelas fugas, pelo discurso que não se deixa demarcar, como certa música que ecoa.

As vertigens, retratos e deslocamentos reforçam que, seu aparente ecletismo é, na verdade, fruto de uma estratégia concentrada, mas que, não assume um determinado centro. Sem o centro, o texto, como o próprio autoretrato, assume e confirma a contradição entre os dois gêneros, optando pela cena da linguagem, a cena do texto, a própria escritura. Desse modo, o leitor aceitando esse "pacto", aceitaria também o texto que escapa do caráter generalista da ciência no discurso intelectualizado das idéias (gênero ensaístico), bem como as características da narrativa ou da rigidez da lógica do biográfico (perfis do romance e da autobiografia). Pensando assim, é possível entender a escolha por uma forma híbrida, ou "terceira forma" ${ }^{3}$, como o próprio semiólogo nomeou - sempre viabilizada pela inscrição do romance - "o romanesco sem o romance".

Assim, a leitura de Roland Barthes par Roland Barthes (1975) que se propõe, nesse trabalho, pauta-se no conceito de escritura como um dos principais no pensamento de Barthes, sem rejeitar o desejo que concilia os eixos do romance através do viés romanesco, também, muitas vezes, reflexivo e transgressor. Desse modo, nesse livro, também, encontramos auto-retratos plurais, conceitos de sujeitos-desviantes que se fabricam no texto de Roland Barthes. Espécie de princípio poético que se assemelha com uma autobiografia, mas que indaga, desconstrói e estremece os pilares do gênero ao ficcionalizar o "eu" (ou "eus"?) adotando múltiplos e diferentes regimes discursivos - eu, tu, ele e a notação "RB", submetendo a identidade a um deslizamento contínuo - vertiginoso e deslocado.

\section{DEZ NOTAS PARA UMA LEI TURA FRAGMENTÁRI A}

“É preciso conceber o escritor (ou o leitor: é a mesma coisa) como um homem perdido em uma galeria de espelhos: ali onde a sua imagem está faltando, ali está a saída, ali está o mundo" [BARTHES, Roland. 1982, p.51].

1. Os leitores escrevem como Roland Barthes o texto de Roland Barthes. “Uma frase, um período, a idéia sob exata forma, a união de conceitos e ato, estamos apaixonados - há, na escuta, um corpo se apresentando, tornando-nos também a nós, imediatamente corporais, sensuais" (SANTOS, 1999, p.96).

2. O corpo plural: "Que corpo? Temos vários." Tenho um corpo digestivo, tenho um corpo nauseante, um terceiro cefalálgico, e assim por diante: sensual, muscular (a mão do escritor), humoral, e, sobretudo: emotivo: que fica emocionado, agitado, entregue ou exaltado, ou atemorizado, sem que nada transpareça. Por outro lado, sou cativado até o fascínio pelo corpo socializado, o corpo mitológico, o corpo artificial (o dos travestis japoneses) e o corpo prostituído (o do ator)" (BARTHES, 1977, p. 68). 
3. O Amador: "o amador (aquele que pratica a pintura, a música, o esporte, a ciência, sem espírito de maestria ou de competição), o Amador reconduz seu gozo (amator: que ama e continua amando); não é de modo algum um herói [...] ele se instala graciosamente (por nada) no significante" (BARTHES, 1977, p. 59).

4. A coincidência: "O fato (biográfico, textual) se abole no significante, porque ele coincide imediatamente com este: escrevendo-me, apenas repito a operação extrema pela qual Balzac, em Sarrasine, fez "coincidir" a castração e a castratura: e ou eu mesmo meu próprio símbolo, sou a história que me acontece [...]" (BARTHES, 1977, p. 64).

5. "Escrevo um texto e o chamo de R. B." (BARTHES, 1977, p.64).

6. A arrogância: "[...] A arrogância circula, como um vinho forte entre os convivas do texto". O intertexto compreende não apenas textos delicadamente escolhidos, secretamente amados, livres, discretos, generosos, mas também textos comuns, triunfantes. Você mesmo pode ser um texto arrogante de um outro texto" (BARTHES, 1977, p. 53-54).

7. O círculo dos fragmentos: "Escrever por fragmentos: os fragmentos são então pedras sobre o contorno do círculo: espalho-me à roda: todo o meu pequeno universo em migalhas; no centro, o quê?" (BARTHES, 1977, p. 101). [...] "Como? Quando se colocam fragmentos em seqüência, nenhuma organização é possível? Sim: o fragmento é como a idéia musical de um ciclo [...] cada peça se basta, e no entanto ele nunca é mais do que o interstício de suas vizinhas: a obra é feita somente de páginas avulsas" (BARTHES, 1977, p. 102).

8. A dupla figura: "Esta obra, em sua continuidade, procede por via de dois movimentos: a linha reta (a repetição, a ampliação, a insistência de uma idéia, de uma posição, de um gosto, de uma imagem) e o ziquezague (o contrapelo, a contramarcha, a contrariedade, a energia reativa, a denegação, a volta de uma ida, o movimento do Z, a letra do desvio). (BARTHES, 1977, p. 98).

9. Quanto a mim, eu: “o sujeito se coloca alhures, e a 'subjetividade' pode voltar num outro trecho da espiral: desconstruída, desunida, deportada, sem ancoragem: por que eu falaria de 'mim', já que 'mim' não é mais 'si'”? Pronomes ditos pessoais: tudo se joga aqui, estou fechado para sempre na liça pronominal: o 'eu' mobiliza o imaginário, o 'você' e o 'ele' a paranóia. Mas também, fugitivamente, conforme o leitor, tudo, como os reflexos de um chamalote, pode revirar-se: em 'quanto a mim', o 'eu' pode não ser o mim, que ele quebra de um modo carnavalesco; posso me chamar de 'você', como Sade o fazia, para destacar em mim o operário, o fabricante, o produtor de escritura, do sujeito da obra (o Autor); por outro lado, não falar de si pode querer dizer: falo de mim como se estivesse um pouco morto, preso numa leve bruma de ênfase paranóica, ou ainda: falo de mim como o ator brechtiano que deve distanciar sua personagem : 'mostrálo', não encarná-lo, dar à sua dicção uma espécie de piparote, cujo efeito é deslocar o pronome de seu nome a imagem de seu suporte, o imaginário de seu espelho (Brecht recomendava ao ator que pensasse todo o seu papel na terceira pessoa). (BARTHES, 1977, p. 179).

10. O jogo, o pastiche: “Dentre as numerosas ilusões que ele cultiva sobre si mesmo, existe esta, tenaz: que ele gosta de jogar, e, portanto, que tem o poder de fazê-lo; ora, ele nunca fez um pastiche (pelo menos voluntariamente), exceto quando estava no liceu [...] embora muitas vezes tivesse tido vontade de o fazer. 
Pode haver uma razão teórica para isso: quando se trata de desmontar o jogo do sujeito, jogar é um método ilusório, e mesmo de efeito contrário ao que se busca: o sujeito de um jogo é mais consistente do que nunca; o verdadeiro jogo não está em mascarar o sujeito, mas em mascarar o próprio jogo". (BARTHES, 1977, p. 152)

'Relato interno', 'duplicação interior', 'composição em abismo', 'construção em abismo', 'estrutura em abismo', 'narração em primeiro e segundo graus' - todas essas denominações se referem à uma técnica narrativa, inspirada em procedimentos encontrados nas artes plásticas (pintura) e, que, posteriormente e com as adaptações necessárias e especificidade de cada forma de arte, chegou à literatura e às outras linguagens ${ }^{4}$. Nesse livro de Barthes, a técnica é utilizada como efeito de um retrato que se pretende traçar, um retrato dentro de outro retrato, como em enclave, uma fabricação com diversas linguagens ou uma narração secundária que se desenvolve a partir da ficção original.

A esses jogos de espelhos, instigando o leitor e o espectador mais atento, Lucien Dallenhach (1991), principal teórico desse conceito, chamou de mise en abyme $e^{5}$, que é "todo fragmento textual que mantém uma relação de semelhança com a obra que o contém", funcionando, nesse caso, como um reflexo ou espelho da proposta semiológica de Barthes.

Alguns estudiosos acreditam que essa forma metanarrativa gera uma sensação de maior ficção (como se o leitor fosse ainda mais atraído para o jogo da criação e do pastiche), porém, alguns teóricos pensam que o recurso alerta o público e o leitor para a "irrealidade" da trama. Em Barthes, essa escritura derradeira, em espiral, abismal e especular ${ }^{6}$ reforça, além desse olhares, também a duplicação ao infinito, a ficção de si, a reflexão por semelhança ou mesmo por contraste. Sempre num jogo de signos, de linguagem.

\section{II. DE ARTI Fí CI OS E DE PENSAMENTOS ESPI RALADOS}

No trajeto da espiral, tudo volta, mas em outro lugar, superior: é então a volta da diferença, a marcha da metáfora; é a ficção. (BARTHES, 1977, p. 96).

Um dos leitmotive insistentes em Roland Barthes por Roland Barthes, ao esvaziar o sujeito da escrita da personalidade civil do autor, pluralizando-o como figura (persona), é o de nos dar a ler, à contraluz, o jogo discursivo, jogo do pastiche:

“[...] matéria fatal do romance e labirinto de redentes nos quais se extravia aquele que fala de si mesmo, o imaginário é assumido por várias máscaras (personae), escalonadas segundo a profundidade do palco (e no entanto ninguém por trás). $O$ livro não escolhe; ele funciona por alternância, avança por lufadas de imaginário simples e de acessos críticos, mas esses mesmos acessos nunca são mais do que efeitos de repercussão; não há imaginário mais puro do que a crítica (de si). A substância deste livro, enfim, é pois totalmente romanesca. A intrusão no discurso do ensaio, de uma terceira pessoa que não remete entretanto a nenhuma criatura fictícia, marca a necessidade de remodelar os gêneros:que o ensaio confesse ser quase um romance: um romance sem nomes próprios" (BARTHES, 1977, p. 129) 
Roland Barthes ao pretender registrar a experiência do autor, não faz mais que capturar fragmentos e arranjá-los, criando um simulacro de inteireza que se oferece ao leitor. Não nos familiarizamos com Barthes através de sua autobiografia, mas sim através de sua crítica que vemos aos poucos compor esse rosto, que não é único e nem coerente, que não é obra de um autor que o entrega acabado, mas é obra do leitor que vai aos poucos descortinando seus traços, inteirando-se de suas cores, pressupondo sua escritura, seu ânimo. É imagem-móvel para cada um que a compõe, que se refaz na releitura ou no contato com aquilo que ainda não foi lido.

$\mathrm{Na}$ contracapa da edição portuguesa de Roland Barthes por Roland Barthes, o crítico confessa em diversas indagações:

“[...] seria interessante - para não dizer divertido - pedir a um escritor que fizesse um dia a própria crítica da sua obra. Concebi este livro com este espírito, como uma espécie de gag, de pastiche de mim mesmo, permitindo todos os divertimentos de um desdobramento. Contudo, ao lançar-me ao trabalho, tudo mudou; puseram-se problemas sérios de teoria e de prática da escrita, tornando um pouco irrisório o simples jogo previsto à partida. Dei-me conta (não imediatamente) de que se me oferecia para encenar, se assim se pode dizer, a relação que pude ter com a minha própria imagem, quer dizer, o meu "imaginário"; e como a minha obra pretérita é a de um ensaísta, o meu imaginário é um imaginário de idéias. Trata-se, em suma, de uma espécie de romance do intelecto. Este romance é verdadeiro? O que eu aí digo é verdadeiramente o que penso? Que é este "eu" que pensa isso? Uma imagem? É sabido que o imaginário é o próprio desconhecimento destas duas novas potências a que se dá o nome de inconsciente e ideologia; meu livro, num sentido, é estúpido: ele sabe-o mas não o diz: é um pouco como se eu fosse o meu próprio Bouvard-etPécuchet".

Desse modo, a escrita paradoxal da revelação autobiográfica em uma literatura que pressupõe a inexistência do autor começa a se dissipar e confirmar aspectos de sua própria crítica ${ }^{7}$. O Barthes que é revelado na leitura não é esse indivíduo que aparece nas biografias clássicas ou nos artigos de jornal. O Barthes que é revelado na leitura-escritura não é exterior à própria obra.

Na edição francesa (1975), diferentemente da edição brasileira com o jogo do duplo na capa, utiliza-se uma pintura do semiólogo. Segundo seu biógrafo, Louis J ean Calvet, Barthes começa a se dedicar à pintura após uma viagem que faz ao Marrocos e Japão, no início da década de 70 . Nesses países descobre uma prática de escrita que arremessa o sujeito na pura fruição da materialidade, na superfície sem fundo das coisas, enfim, uma prática que não "caia diretamente na armadilha da linguagem" - nesses países, escreve Calvet, "o escritor descobrira uma espécie de prolongamento da

escritura, transmutação dos movimentos da mão que formam letras: a caligrafia" (CALVET, 1993, p. 217). Ou seja, sugere e encaminha uma leitura que se lança ao grafismo, ao prolongamento da escritura de maneira quase automática, no significante, na forma, tomando o ritmo do conteúdo.

Como no quadro "As Meninas", de Velásquez (que Foucault comenta) em que o pintor Barroco, por um jogo de espelhos, aparece no centro da tela, Barthes está dentro da obra. Não apenas nos momentos em que ostensivamente se expõe nas fotos ou fragmentos ou nas pinturas, mas também, em que se lê como obtuso. Não mais autor, mas personagem de si mesmo. Não mais idêntico a si mesmo, imitação do autor, mas outro em permanente trabalho semiológico. E por isso 
mesmo questiona ironicamente: "O título desta coleção ( $\mathrm{X}$ por ele mesmo) tem um alcance analítico: eu por mim mesmo? [...] Como é que os raios do espelho reverberam, repercutem sobre mim?" (BARTHES, 1977, p.163).

Jonathan Culler vê o livro Roland Barthes por Roland Barthes como "um relato estranhamente imparcial da vida e da obra de um certo "Roland Barthes" por fugir às convenções da autobiografia (1988, p.13). Como o próprio semiólogo afirma:

\begin{abstract}
“Escrever é abalar o sentido do mundo, aí, fazer uma interrogação indireta, que o escritor, em vista de um suspense derradeiro, abstém-se de responder. A resposta é dada por cada um de nós, que para aí transporta sua história, sua linguagem, sua liberdade; mas como história, linguagem e liberdade mudam infinitamente, a resposta do mundo do escritor é infinita: não se pára jamais de responder ao que foi escrito longe de toda resposta" (BARTHES, 1987, p.5).
\end{abstract}

Nesse fragmento, a leitura de Barthes sobre Racine traça a possibilidade, como também em Roland Barthes por Roland Barthes, de se extrair um estudo da linguagem, uma crítica que transita por espaços incertos e mutantes, a cada manobra lingüística, um verdadeiro "inferno da significação" semelhante a sua postura na tentativa de se auto retratar. "A crítica de autor é [...] uma semiologia que não ousa dizer seu nome. Se ousasse, conheceria pelo menos seus limites, divulgaria suas escolhas; ela saberia que deve sempre contar com dois arbitrários é, então, assumi-los. De um lado, para um significante existem sempre vários significados possíveis: os signos são extremamente ambíguos, o deciframento é sempre uma escolha" (BARTHES, 1987, p.152).

Releitura de si mesmo e de sua própria crítica, o livro é construído como o conceito de escritura, que é o da palavra poética como desconstrução do "eu", como pluralidade de códigos que a escritura põe em jogo e exige, do sujeito, um vasto saber. Para penetrar no mundo desse retrato-escritura, que é o da palavra poética, é preciso mudar o método de observação, ajustar o foco, saber se posicionar e avaliar as distâncias do eu, porque o sentido, como fogo, ou a "poética do fogo", como a denomina Barchelard, é uma metáfora da luz e das paixões e só se manifesta por dois processos: o da friç̧ão ou o do choque, e ambos produzem faíscas e modulações. Os fragmentos, então, em Roland Barthes por Roland Barthes, adquirem, pelo novo contato, uma outra temperatura, captado somente pela percepção sensível, poética.

A dissimulação do eu, em ato de escritura, assim, revela de alguma forma a dispersão e a reorganização sígnica, é uma atividade de motivação semiótica de sobreposição e entrecruzamento de códigos e discursos que possibilita, à leitura, múltiplas travessias de sentido. Em Fragmentos de uma Poética do Fogo (1990), Gaston Barchelard, ao tratar da arte poética, faz uma análise dos mecanismos necessários a sua observação e comenta que o poético não pode ser apreendido apenas por um olhar cientificista, que a sua detecção implica uma imaginação capaz de ver imagens, e não idéias, de se "entregar à consciência caleidoscópica".

Caleidoscópica, essa coreografia sígnica do eu, materializada pela escritura, pelo deslocamento contínuo de formas já exauridas ${ }^{8}$, que se transmutam no espaço cênico da página, esconde uma outra intencionalidade discursiva: fugir às garras do poder que segundo o próprio Barthes, está emboscado em todo e qualquer 
discurso. Por isso mesmo, para traçar um auto-retrato, Barthes praticou o que discute e propõe - o jogo - por todo o seu trabalho textual, como em Le plaisir du texte: “O prazer não é uma pequena fruição? A fruição é apenas um prazer extremo? O prazer é apenas uma fruição enfraquecida, aceita e desviada através de um escalonamento de conciliações? A fruição não é senão um prazer brutal, imediato (sem mediação)?" (BARTHES, 1973, p.32-33).

Percebe-se, então, no perfil em que se traça, que o procedimento adotado é o desvio, a trapaça apontada por ele mesmo, a equivocidade, a ambigüidade e a polissemia, únicas vias, tudo indica, capazes de ludibriar as normas rígidas da autobiografia, de certa gramática perversa.

Esse auto-retrato, descrito assim, pode ser definido além de semelhante a sua própria escritura, define-se como um texto-retrato escriptível ${ }^{9}$, um texto que exige, para a sua decodificação, uma desconstrução derridiana. Nesse processo de um eu-escritura, os elementos constitutivos partem de um rearranjo, de uma variação de textos anteriores, buscando uma voz cujo eco traz em uma vibração, um novo sentido. E por isso mesmo diz:

"Em tudo isto existem riscos de recesso: o sujeito fala de si (risco de psicologismo, risco de enfatuação), ele enuncia por fragmentos (risco de aforismo, risco de arrogância). Este livro é feito daquilo que não conheço: o inconsciente e a ideologia, coisas que só se falam pela voz dos outros. Não posso colocar em cena (em texto), como tais, o simbólico e o ideológico que me atravessam, já que sou sua mancha cega (o que me pertence propriamente é meu imaginário, é minha fantasmática: daí este livro). Da psicanálise e da crítica política, só posso dispor à maneira de Orfeu: sem nunca me voltar para trás, sem nunca as olhar, as decifrar (ou muito pouco: apenas o suficiente para relançar minha interpretação na corrida do imaginário)". (BARTHES, 1977, p.162-163)

Essa exploração do auto-retrato pela linguagem é a sua tarefa e a sua fruição. Porque "o texto que o senhor escreve tem de me dar prova de que ele me deseja. Essa prova existe: é a escritura. A escritura é isto: a ciência das fruições da linguagem, seu kama-sutra (desta ciência, só há um tratado: a própria escritura)" (BARTHES, 1973, p.14). Munido deste desejo, logo no início do livro, Barthes esclarece as relações entre corpo, texto e escritura que perpassarão pelo livro como um todo:

“[...] Não se encontrarão pois aqui, mescladas ao romance familiar, mais do que as figurações de uma pré-história do corpo - desse corpo que se encaminha para o trabalho, para o gozo da escritura. Pois tal é o sentido teórico dessa limitação: manifestar que o tempo da narrativa (da imageria) termina com a juventude do sujeito: não há biografia a não ser a da vida improdutiva. Desde que produzo, desde que escrevo, é o próprio Texto que me despoja (felizmente) de minha duração narrativa. O Texto nada pode contar; ele carrega meu corpo para outra parte, para longe de minha pessoa imaginária, em direção a uma espécie de língua sem memória que já é a do Povo, da massa insubjetiva (ou do sujeito generalizado), mesmo se dela ainda estou separado por meu modo de escrever) [...]" (BARTHES, 1977, p.8).

Retomado em um eu como metáfora do corpo, pode-se dizer que a questão do autor reflete no que se esconde ou se projeta do corpo do autor. Isso pode ser ilustrado com a afirmativa que comenta e serve como subtítulo a autobiografia de Roland Barthes por Roland Barthes na contracapa, quando diz: "Tudo isso dever ser 
considerado como dito por um personagem de romance". De certa forma, em seus textos e cursos escritos nos seus últimos dois anos de vida, Roland Barthes confessa, mesmo que pelo viés de um estudo sobre o trabalho de escritura do romance, a sua vontade de escrever a Obra, seu desejo de romancista.

No famoso ensaio A Morte do autor, o semiólogo já apontou que o autor é uma categoria historicamente marcada pela lógica burguesa da propriedade, e a lógica do leitor deveria se impor a essa lógica, levando em consideração o Texto por meio de leituras e releituras futuras, e não a sobrevivência de um Nome, de uma personalidade. Essa mesma discussão e retorno ao "o-homem-e-a-obra" foi um dos célebres textos de Foucault, intitulado O que é um autor? (1992).

O autor, nessa perspectiva semiológica, "não é uma testemunha,[...] mas um ator de escrita" (BARTHES, 2005, p.170). A essa mesma experiência de Roland Barthes por Roland Barthes foi explorada por Barthes na escritura proustiana "uma escrita da vida" - que ele chamou de biografemática ${ }^{10}$, situação onde o Texto fragmenta o sujeito, o divide, chegando ao ponto de uma pulverização.

Os fragmentos ou lexias, pulverizados pelo corpo do texto, comporiam um todo homogêneo. O semiólogo cria uma tipologia dos papéis "varridos pela escrita da vida", scribens ${ }^{11}$ e persona ${ }^{12}$ unem-se de forma que qualquer texto, diário ou mesmo álbum de fragmentos, possam se tornar Obra. Esses seriam, portanto, vários "eus" tecidos, em que um implicaria o outro, a fuga de sua própria fotografia.

Barthes lembra que essa biografemática, é ao mesmo tempo, indissoluvelmente, uma tanatografia. Essa leitura aproxima-se das teorias derridianas sobre o trabalho de luto que envolve a escrita. A escrita, segundo Derrida, é parricida a partir do momento em que o Texto se torna independente daquele que escreve podendo servir como "veneno" ao seu próprio autor, àquele que assina. O corpo que escreveu, apaga-se para dar lugar à Obra. Roland Barthes por Roland Barthes revela esse apagamento do "eu" em benefício do texto, justamente a "abertura de um espaço onde o sujeito da escrita está sempre a desaparecer" (FOUCAULT, 1992, p.35). As fotografias aleatórias presas ao livro, misturam-se e reforçam o imaginário de imagens detido na entrada da vida produtiva, mas esse imaginário revelar-se-ia como a própria escritura.

Os constantes deslocamentos desse eu fragmentado e das imagens que se reestruturam em diferentes combinatórias levam a uma produção de sentidos, ou como ele mesmo quis, a um outro nível, o da significância, ou ao "nível obtuso". Não é por acaso, de resto, que o próprio Roland Barthes afirma: "toda a biografia é um romance que não ousa dizer o seu nome" (1975, p.64).

Esse livro seria, então, o corpo e a letra em confronto físico na busca do texto de gozo, do texto-retrato (ou o retrato enquanto texto) que tocará a interioridade sensível do leitor, um texto capaz de fazê-lo ouvir além da imagem acústica do signo. "Tudo isso define muito bem a ação do significante ou o significante em ação" (BARTHES, 1990, p.83). A duplicidade presente no título é o próprio jogo discursivo frente a um espelho e que reforçando e produzindo um interstício por onde escapa o sujeito transferindo para o leitor o vazio da linguagem; feito os estudos em Sade, Fourier, Loyola "colhido na malhas do metalivro, seu livro é um sujeito, o significado é dilatório, retirado continuamente 
para mais longe: estende-se sozinho, a perder de vista, no futuro do livro, o significante". (BARTHES, 1990, p.86).

O título, paratexto por excelência segundo a teoria genettiana, encaminha a leitura para sugerir o sujeito que desaparece na sua própria duplicidade, tornandose um fantasma, o duplo, a sombra ou qualquer representação que não é ele mesmo, espécie de sensação ausente cuja presença só pode ser percebida entre as suas próprias palavras. Na verdade, como o próprio título, a repetição estilística (tautológica), reforça que o sujeito está sempre ao lado de si mesmo, mas como ausência.

O sujeito-ausente, na verdade, coloca-se em cena através de diversos "efeitos do real" 13 seja através do álbum de fotografias, seja através de fragmentos intitulados, de tal modo organizados que constituem um metatexto fragmentário que se refere ao próprio teatro do imaginário. Para tanto, Roland Barthes estabelece uma utilização multiforme dos pronomes pessoais, e alguns procedimentos enunciativos que atravessam esses fragmentos: o "eu" que mobiliza o imaginário; o "ele" - colocado à distância e que permite ao sujeito tornar-se ausente de si mesmo; e o "tu" que aparece nas seqüências de auto-acusação. Por fim, a notação "R.B." aparece com freqüência para desfazer a ambigüidade do pronome de 3 a pessoa do singular.

\section{EM BUSCA DE UM OUTRO: I NCONCLUSÕES}

"Tudo isso deve ser considerado como se fosse dito por uma personagem de romance". Esta afirmação sintetiza a direção do fascínio de qualquer leitor que se aproxima do livro Roland Barthes por Roland Barthes; a volta ao objeto de estudo desse recorte/ensaio: o auto-retrato, ao interessante jogo discursivo e sutil dos "eus" que se estabelecem entre o crítico e o escritor, objeto de olhares.

Se a partir da afirmação anterior é possível entender que a ficção barthesiana é construída a partir de pactos, a partir de diálogos entre autor, crítico e personagem, esta leitura que se volta para a descoberta de retratos é uma partilha entre leitor sagaz e paciente; espécie de inventor de associações imprevistas (obtusas) e divulgador de um escritor/crítico que se revela como se novo fosse a cada associação inesperada.

Entre os disfarces do artista e do discurso, nessas leituras há um cruzamento irônico de caminhos difíceis de mapear, porém ambos se mascaram para entreolharem-se com curiosidade e é difícil saber onde a enunciação do primeiro foi descoberta/construída pela sagacidade do segundo: nesse cruzamento, o autor é nome guardado no tempo, mas as leituras plurais são possibilidades de revelações do que está guardado para a criação de um valor presente.

As leituras de Roland Barthes par Roland Barthes desconstroem o autor (como seu próprio autor) para descobrir nele o leitor de outros textos (retratos) que atuam como sementes de sua escritura romanesca. Entre o biografema e o romanesco, entre o ensaio e a autobiografia, entre disfarces e crítica, apenas o afrontamento os desvela ou a fronteira difusa que se coloca para o leitor como desafio instigante a descobrir os limites que os envolvem o que se pensa como obtuso. 
Ver ou ler esses retratos prometem apontar em Barthes, o caminho que o transforma de autor em leitor de ficção, de romancista em semiólogo. Neste livro, o artista-Barthes e o crítico se desafiam para proporcionarem, ao leitor de ambos, uma revisão da literatura a partir da leitura responsável pela descoberta do autor nos textos que lê e pelo crítico na maneira como descobre esse autor/leitor. Entre o artista-camaleônico e o semiólogo há apenas um disfarce de autores, ambos são leitores. 


\section{Notas}

${ }^{1}$ Termo proposto por Roland Barthes (1980) para designar, na imagem fotográfica, um nível de sentido não intencional, próprio à subjetividade do analista e ao jogo da figura. [...] $O$ punctum só está presente na imagem se o analista o nota e o erige como lugar de significância; ele aliás, como seu nome indica, (um ponto) sempre bem localizável. Assemelha-se a noção de "sentido obtuso."

2 Remeto aqui ao clássico livro O Pacto autobiográfico, de Philippe Lejeune que entende o nome próprio, o trabalho sobre ele e sobre a assinatura como objetos profundos da autobiografia, isto é, afirmação da identidade autor-narrador-personagem, remetendo em última instância ao nome do autor na capa do livro [LEJ EUNE, 2008, p.30].

${ }^{3}$ Ao fazer uma análise sobre alguns fotogramas de Eisensten, Barthes, no ensaio o "Terceiro Sentido", classifica o sentido em três níveis: o nível da comunicação, que é o informativo; o nível do simbólico, que é o da representação, já estratificado, a que denomina nível da significação, e um terceiro nível, que, errático e teimoso", se opõe aos dois primeiros e que Barthes chama de nível da significância, termo que aponta para o significante do signo, objeto de interesse dos estudos de Barthes.[ In: L'obvie et l'obtus. p. 280.]

4 Ver o livro HEATH, Stephen. Vertige du Déplacement. Lecture de Barthes.Paris. Fayard. 1974.

5 A mise en abyme consiste num processo de reflexividade literária, de duplicação especular. Tal auto-representação pode ser total ou parcial, mas também pode ser clara ou simbólica, indireta. A definição que Dallenbach em Le récit spéculaire propõe para a "mise en abyme" ressalta que o fragmento reflexivo deve espelhar "conjunto do relato", o que não inclui apenas o enunciado, mas também o processo de enunciação e o código em que é feito o relato. Diz ele que: "Um espelhamento é um enunciado que reenvia ao enunciado, à enunciação e ao código" [DALLENGACH, 1977, p. 62].

${ }^{6}$ Essa mesma leitura pode ser melhor aprofundada no livro HEATH, Stephen. Vertige du Déplacement. Lecture de Barthes.Paris. Fayard.1974.

${ }^{7}$ Ver ensaio "A Morte do autor".

${ }^{8}$ Para Barthes "as forças de liberdade que residem na literatura não dependem da pessoa civil, do engajamento político do escritor que, afinal, é apenas um "senhor" entre outros, nem mesmo no conteúdo doutrinal de sua obra, mas no trabalho de deslocamento que ele exerce sobre a língua [...]" [ In: BARTHES, R. Leçon. Paris. Seuil. p.17].

9 Texto para Barthes "não é um produto estético, é uma prática significante; não é uma estrutura, é uma estruturação; não é um objeto, é um trabalho e um jogo; não é um conjunto de signos fechados, dotado de um sentido que tentássemos encontrar, é um volume de marcas em deslocamento, a instância do Texto não é a significação, mas o Significante, na acepção semiótica e psicanalítica do termo". Roland Barthes. In: A Aventura Semiológica. ( 1987, p.14). Ainda dentro dessa tipologia desenvolvida por Barthes existem os "textos de prazer" e "textos de gozo" situados na temporalidade da leitura. Os textos de prazer são também chamados de "clássicos" ou "legíveis" - não oferecem resistência, proporcionam uma leitura fluente e tranqüila, desimpedida, convidam o espectador a pular fragmentos de imagens, sem perda de entendimento; já os textos de gozo - igualmente chamados de "modernos" ou "escrevíveis" - exigem uma leitura mais atenta, sob pena de, à não obediência dessa exigência, punir o leitor com o tédio, a improdutividade e, finalmente, ao abandono da leitura. Portanto, fiz referência à leitura dos possíveis retratos de Roland Barthes, associando ao conceito de "textos de gozo" - textos escrevíveis. Um texto que nós construímos ao olhar o auto-retrato (mas não está presente), aberto a um plural ilimitado e só se torna possível pelo engajamento radical da produtividade do espectador/leitor. Um olhar, extremamente, semiológico, vertiginoso e escrevível.

10 O biografema, segundo Barthes, nunca é uma verdade objetiva: “O biografema nada mais é do que anammese factícia: a que eu empresto ao autor que amo". A biografemática "ciência" do biografema - teria como objeto pormenores isolados, que comporiam uma 
biografia descontínua; essa "biografia" diferiria da biografia-destino, onde tudo se liga, fazendo sentido. O biografema é o detalhe insignificante, fosco; a narrativa e a personagem no grau zero, meras virtualidades de significação. Por seu aspecto sensual, o biografema convida o leitor a fantasmar; a compor, com esses fragmentos, um outro texto que é, ao mesmo tempo, do autor amado e dele mesmo - leitor. [PERRONE-MOISÉS, 1983, p. 15]

11 Scribens: “o eu que está na prática da escrita, que está escrevendo, que vive cotidianamente a escrita" (BARTHES, 2005, p.174).

12 Persona: “a pessoa civil, cotidiana, privada, que "vive" sem escrever" [BARTHES, 2005, p. 174].

13 BARTHES, Roland. O efeito de real. In: Literatura e Realidade. (O que é realismo?). pp. 87-98 O realismo, segundo TODOROV na apresentação desse livro diz: " O realismo [...] tem como função dissimular qualquer regras dar-nos a impressão de que o discurso é em si mesmo perfeitamente transparente (quase seria possível dizer-se inexistente) e de que estamos perante o vivido - um fragmento de vida. O realismo é um tipo de discurso que pretende fazer-se passar por outro; um discurso em que o ser e o parecer não coincidem". [1984, p.11]. 


\section{REFERÊNCI AS BIBLI OGRÁFI CAS:}

BACHELARD, Gaston. Fragmentos de uma poética do fogo. São Paulo. Brasiliense. 1990.

BARTHES, Roland. . Sade, Fourier, Loyola. São Paulo. Brasiliense. 1990.

. Escritores, Intelectuais, Professores e outros ensaios. Lisboa. Presença. 1975.

Roland Barthes par Roland Barthes. Paris. Seuil. 1975.

Roland Barthes por Roland Barthes. Lisboa. Edições 70. 1976.

Le plaisir du texte. Paris. Seuil.1973.

Roland Barthes por Roland Barthes. São Paulo. Cultrix. 1977.

Leçon. Paris. Seuil. 1978.

Literatura e Realidade. (0 que é realismo?). Lisboa. Publicações Dom Quixote. 1984.

A Câmera Clara. Rio de Janeiro: Nova Fronteira, 1984.

Sobre Racine. Porto Alegre. L\&PM. 1987.

A Aventura Semiológica. Lisboa. Edições 70, 1987.

Sollers Escritor. Rio de Janeiro. Tempo brasileiro. Fortaleza. Universidade Federal do Ceará.1982. L'obvie et l'obtus. Essais critiques III. Paris. Seuil. 1982.

$\overline{2} \overline{0} \overline{0} \overline{5}$.

O Rumor da Língua. São Paulo: Martins Fontes, 2004.

CALVET, Louis-J ean. Roland Barthes uma biografia. São Paulo. Sciliano. 1993

CULLER, J onathan. As idéias de Barthes. São Paulo. Cultrix. 1988.

DALLENBACH, Lucien. Intertexto e autotexto. In: Intertextualidades. Coimbra. Almedina. 1979.

Le récit spéculaire. Essai sur la mise en abyme. Paris. Seuil. 1977.

FOUCAULT, Michel. O que é um autor? Lisboa. Veja Passagens. 1992.

GERARD, Genette. Palimpsestes. La littérature au second degré. Paris:

Seuil. 1982.

HEATH, Stephen. Vertige du Déplacement. Lecture de Barthes. Paris.

Fayard.1974.

LEJEUNE, Philippe. O pacto autobiográfico. Belo Horizonte. Ed. UFMG. 2008.

PERRONE-MOISÉS, Leila. Barthes: o saber com sabor. Brasiliense. São Paulo, 1983.

SANTOS, Roberto Corrêa dos. Barthes, a força, a brandura. In: Modos de saber, modos de adoecer. Belo Horizonte. Ed. UFMG. 1999.

SONTAG, Susan. L'écriture même: à propos de Barthes. Paris. Christian Bourgois Éditeur. 1982. 